\title{
The use of univariate cross prediction methods in the breeding of a clonally reproduced crop (Solanum tuberosum)
}

\author{
P. D. S. Caligari* and J. Brown
}

Scottish Crop Research Institute, Pentlandfield, Roslin, Midlothian EH25 9RF, Scotland.

The progenies from eight potato crosses were examined. A number of genotypes from each cross were visually assessed, by four breeders, after they had been grown from true-seed in a glasshouse and from seed-tubers in the field, at two locations, in three consecutive years.

It was found that the mean and square root of the variance $(\sigma)$ obtained from the data collected in any of the environments provided a good prediction of the number of clones in each cross that would exceed (or equal) a given target value. $\sigma$ added increasingly to the accuracy of the prediction as the target value increased, but was not a major component in such predictions. When the predictions were used to provide a ranking of the crosses, the rank correlations showed good agreement between the different environments and between observed and expected ranks.

\section{INTRODUCTION}

Methods of predicting the distribution of recombinant inbred lines using early generations of crosses have been proposed by Jinks, Pooni and colleagues (Jinks and Pooni, 1976; Pooni and Jinks, 1978). These methods have been applied to a variety of inbreeding species, particularly wheat (Snape, 1982) and barley (Thomas and Tapsell, 1983; Tapsell and Thomas, 1983). The use of such methods has been proposed in inbreeding species to allow the selection of the progenies with highest probabilities of producing desirable recombinant lines in plant breeding. In this way the problems associated with early generation selection in such species are avoided. These problems fall into two main categories (a) the difficulty of selecting in highly heterozygous material, where dominance effects can be large, for genotypes that will produce superior homozygous lines, and (b) the inaccuracy of selecting on small plots (initially, often on individual plants) because of the error variance and sampling variation, as well as the competitive effects of the surrounding plots, which are of different genotypes, (Powell, Caligari, Goudappel and Thomas, 1985; Caligari and Powell, 1986).

The prediction methods have been further extended to cover second cycle hybrids (Pooni and

* Present address: Department of Agricultural Botany, The University of Reading, Whiteknights, Reading RG6 2AS, U.K.
Jinks, 1985; Pooni, Jinks and Yohannes, 1985). In addition other workers have shown, particularly in barley, that small numbers of doubled haploid lines produced from different crosses may be used in making predictions (Reinbergs, Park and Song, 1976; Simpson and Snape, 1979; Caligari, Powell and Jinks, 1985; Powell, Caligari, McNicol and Jinks, 1985). The production of doubled haploids gives a sample of inbred lines which are used to provide an estimate of the population mean and additive genetical variance and hence the distribution of inbred lines that would be expected from a cross.

Thus far such cross prediction methods have not been considered in relation to the breeding of clonally reproduced crops such as potatoes, (Solanum tuberosum). This may perhaps in part be due to the fact that heterozygosity is not a problem, in other words, although the initial true seeds are all genetically unique and highly heterozygous, they are subsequently multiplied clonally and so are fixed in the sense that they are the genotypes which may be commercially exploited. For a description of the Scottish Crop Research Institute (SCRI) potato breeding programme see Holden, 1977 and Mackay, 1982. However, all the other problems of selection efficiency are still pertinent and studies have shown that such conventional phenotypic selection in the early generations is relatively ineffective (Brown, Caligari, Mackay 
and Swan, 1984; Brown and Caligari, 1986; Brown, Caligari, Mackay and Swan, 1986). It would therefore seem appropriate to investigate cross prediction methods in potatoes, particularly as Brown, Caligari and Mackay (1986) have reported that progeny means were repeatable over the early generations, even though the environments in which different generations were raised were as diverse as seedlings in small pots in a glasshouse to material grown in the field from tubers.

\section{MATERIAL AND METHODS}

The progenies of eight potato crosses, chosen as representative of the material normally assessed in the commercial breeding programme at SCRI, were examined. They were also the same crosses as reported by Brown et al. (1984), Brown and Caligari (1986), Brown et al. (1986) and Brown, Caligari and Mackay (1986). The crosses are identified by the codes $\mathrm{C} 1$ to $\mathrm{C} 8$.

The growing conditions and experimental designs used for the seedlings in the glasshouse (GH) and clones in the field for the first clonal year were given by Brown et al. (1984), while those for the second clonal year were given in Brown et al. (1986). The details are thus only reported briefly here. In 1981, 400 seeds from each of the eight crosses were sown in pans. After three weeks, 200 randomly taken seedlings were pricked out, transplanted into $10 \mathrm{~cm}$ square pots and grown to maturity in an aphid-proof glasshouse. The following year (1982) each genotype which produced tubers was grown in a field experiment with single plant randomisation at two locations, Blythbank (BB), a high-grade seed-tuber production site, and the Murrays Farm (MURR), a ware production site. Genotypes which produced sufficient tubers were planted in two completely randomised blocks at both sites. BB is the location used by SCRI for the production of healthy seed-tuber stocks. It is also, however, the only location where clonal assessments are usually carried out in the first two clonal generations of the commercial breeding programme. MURR, on the other hand, is used for yield trials of the more advanced breeding material. The BB site is always planted later and harvested earlier than the MURR site in order to reduce the possible spread of aphid borne viruses.

In 1983 it was not possible to grow all the material that had previously been handled, therefore in the second clonal year each cross was represented by 70 randomly chosen clones. These were grown at both BB and MURR in two com- pletely randomised blocks with each clone, in each block, being represented by a three-tuber plot. In 1984 the number of clones that could be managed again had to be reduced and so in each cross they were randomly reduced to 25 . These clones were again grown at the two sites in two completely randomised blocks but within each block, each clone was grown in five-tuber plots.

Five commercial control cultivars were included in the randomisations in 1982, 1983 and 1984. In these years each control cultivar was grown a number of times within each of the two blocks.

Plots were harvested individually and the tubers were visually assessed by four potato breeders on a 1-9 scale of increasing commercial acceptability. Visual assessment took into account all the features that were observable to provide an overall measure of commercial suitability, such as overall tuber shape, regularity of shape, size, depth of eyes, and presence or absence of defects such as growth cracks, premature sprouting, persistent stolons etc. Although yield is not normally recorded in the early stages of a breeding scheme it is inevitably taken into account with such visual appraisal. Visual appraisal is by its nature subjective, but it has been shown that different breeders' scores were highly correlated between the four breeders in any of the environments (Brown et al. 1984) and hence only mean scores, averaged over breeders, were considered here.

\section{RESULTS AND DISCUSSION}

In 1983 the number of clones per progeny had been reduced to 70 and therefore only these clones were used to form the basis of predictions. The progeny means and square roots of the variances $(\sigma)$ of these 70 clones for the first three years are given in table 1 . In the glasshouse no replication was possible, since each true-seed is unique, and hence only the total between clone variation was available, i.e., the phenotypic variance, the square root of which is given $\left(\sigma_{P}\right)$. In the first clonal year the replicates were confounded with the mother tuber size and hence again no true replicate variance was available to correct the phenotypic variance for environmental effects. In the second clonal year, however, as true replication was possible the square root of the genotypic variance $\left(\sigma_{G}\right)$ is given along with that from the phenotypic variance.

The means and $\sigma$ 's given in table 1 were used, following the methods of Jinks and Pooni (1976), 
Table 1 Mean $(\bar{x})$ and standard deviation (i.e., $\sigma_{P}$-the square root of the between clone variance) estimated from 70 clones for each of eight progenies. In the SCY true replication was present, thus it was possible to estimate $\sigma_{G}$, the between clone variance having removed the environmental component i.e. leaving the genetic component

\begin{tabular}{|c|c|c|c|c|c|c|c|c|c|c|c|c|}
\hline \multirow[b]{3}{*}{ Progeny } & \multirow{2}{*}{\multicolumn{2}{|c|}{$\begin{array}{c}1981 \\
\mathrm{GH}\end{array}$}} & \multicolumn{5}{|c|}{ FCY (1982) } & \multicolumn{5}{|c|}{ SCY (1983) } \\
\hline & & & \multicolumn{2}{|c|}{ BB } & \multicolumn{3}{|c|}{ MURR } & \multicolumn{2}{|c|}{ BB } & \multicolumn{3}{|c|}{ MURR } \\
\hline & $\bar{x}$ & $\sigma_{P}$ & $\bar{x}$ & $\sigma_{P}$ & $\bar{x}$ & $\sigma_{P}$ & $\bar{x}$ & $\sigma_{G}$ & $\sigma_{P}$ & $\bar{x}$ & $\sigma_{G}$ & $\sigma_{P}$ \\
\hline $\mathrm{C} 1$ & $4 \cdot 36$ & $1 \cdot 52$ & $3 \cdot 43$ & $0 \cdot 86$ & $3 \cdot 75$ & 0.85 & $4 \cdot 07$ & 0.79 & $1 \cdot 11$ & $3 \cdot 61$ & 0.58 & 0.91 \\
\hline $\mathrm{C} 2$ & $4 \cdot 01$ & 1.65 & $3 \cdot 34$ & $1 \cdot 25$ & $3 \cdot 50$ & $1 \cdot 22$ & $3 \cdot 41$ & 0.40 & 0.87 & $3 \cdot 02$ & 0.79 & 1.05 \\
\hline C 3 & 3.61 & $1 \cdot 50$ & $2 \cdot 87$ & 0.87 & 3.64 & 0.98 & $3 \cdot 13$ & 0.00 & 0.77 & $3 \cdot 20$ & 0.46 & 0.84 \\
\hline $\mathrm{C} 4$ & $4 \cdot 17$ & $1 \cdot 23$ & $3 \cdot 31$ & $1 \cdot 05$ & $3 \cdot 72$ & 0.90 & $3 \cdot 29$ & 0.70 & $1 \cdot 05$ & 3.07 & 0.65 & 0.95 \\
\hline $\mathrm{C} 5$ & 3.04 & 0.91 & $2 \cdot 90$ & 0.80 & $3 \cdot 33$ & 0.77 & $3 \cdot 40$ & 0.58 & 0.97 & $2 \cdot 92$ & 0.59 & 0.91 \\
\hline C6 & 3.68 & $1 \cdot 52$ & $3 \cdot 55$ & 0.99 & $3 \cdot 71$ & 1.06 & $3 \cdot 90$ & 0.61 & 0.99 & $3 \cdot 53$ & 0.76 & $1 \cdot 03$ \\
\hline $\mathrm{C} 7$ & $4 \cdot 21$ & $1 \cdot 36$ & $3 \cdot 95$ & $1 \cdot 27$ & $4 \cdot 22$ & 1.09 & $4 \cdot 10$ & 0.61 & 0.99 & $3 \cdot 53$ & 0.62 & 0.94 \\
\hline $\mathrm{C} 8$ & $3 \cdot 29$ & 1.44 & $2 \cdot 72$ & $1 \cdot 12$ & $2 \cdot 43$ & 0.81 & $2 \cdot 67$ & 0.51 & $1 \cdot 06$ & $2 \cdot 37$ & 0.53 & 0.88 \\
\hline
\end{tabular}

to calculate the proportion of lines expected to transgress particular target values. The probabilities can be estimated as the sum of the normal probability integrals corresponding to the value:

$$
\frac{T-\bar{X}}{\sigma} \text { or } \frac{\bar{X}-T}{\sigma}
$$

depending on whether the predictions are for values greater than (or equal to) or less than (or equal to) the target and where $T$ stands for the target value and $\bar{x}$ is the mean.

Initially, a visual preference score of 5.0 was taken as the target value. This value was chosen since on the original 1-9 scale of assessment a score of 5 or greater represented the level above which a clone would have been retained in the normal selection process within the breeding programme. The preference scores of the five commercial cultivars, included in the experiments, are given in table 2. Inspection of the means suggests that a target value of 5 would result in the selection of clones that would be at least as good as these widely grown commercial cultivars.

The predicted proportions of clones falling into the category of greater than (or equal to) an average score of 5.0 are given in table 3 for each of the three years and for the two sites. The predictions for 1983 are shown based on the genotypic as well as on the total phenotypic variance. The observed proportions, given in the lower part of the table, are based on all the clones raised on each occasion i.e., 200 clones in 1981 and 1982, 70 clones in 1983 and 25 clones in 1984. It should be noted that the clones used for prediction were not independant of those providing the observed results, which can, of course, lead to spuriously high correspondence between observed and predicted numbers within the same environment. The predicted and observed results were correlated and the estimated coefficients are given in table 4. All the correlations were positive and were generally quite high. It should be noted, however, that some of the correlations although close to significance were not formally so at the 5 per cent level. This was mainly due to the correlation being based on only eight crosses but the consistency and magnitude of their average values shows them to be meaningful. Clearly any of the environments, even the most atypical of normal agricultural growing conditions, i.e., seedlings grown in small pots in the glasshouse, give reasonable predictions. This contrasts with the findings in barley (Caligari $e t$ al., 1985; Powell, Caligari, Phillips and Jinks, 1986) where significant genotype by environment interactions were found to affect predictions.

The use of the phenotypic, compared with the genotypic, variance is also of interest. Although the genotypic variance should, on theoretical

Table 2 Mean visual appraisal scores for the commercial control cultivars

\begin{tabular}{|c|c|c|c|c|c|c|}
\hline \multirow[b]{2}{*}{ Cultivar } & \multicolumn{2}{|c|}{1982} & \multicolumn{2}{|c|}{1983} & \multicolumn{2}{|c|}{1984} \\
\hline & BB & MURR & BB & MURR & BB & MURR \\
\hline P. Crown & 3.58 & 3.93 & $3 \cdot 62$ & 3.87 & $5 \cdot 37$ & $5 \cdot 64$ \\
\hline P. Dell & 3.96 & $4 \cdot 06$ & $4 \cdot 64$ & $4 \cdot 40$ & $6 \cdot 13$ & $6 \cdot 34$ \\
\hline P. Squire & $3 \cdot 79$ & $3 \cdot 10$ & $3 \cdot 90$ & $4 \cdot 04$ & $4 \cdot 62$ & $5 \cdot 36$ \\
\hline M. Piper & $4 \cdot 75$ & $5 \cdot 28$ & $5 \cdot 71$ & $4 \cdot 96$ & $4 \cdot 75$ & $4 \cdot 74$ \\
\hline Desiree & 3.67 & $3 \cdot 25$ & $3 \cdot 87$ & $3 \cdot 63$ & $4 \cdot 87$ & $4 \cdot 94$ \\
\hline
\end{tabular}


Table 3 Predicted and observed proportions of clones falling into the category of mean score greater than (or equal to) $5 \cdot 0$

a. Predicted using $\bar{x}$ and $\sigma$.

\begin{tabular}{|c|c|c|c|c|c|c|c|}
\hline \multirow[b]{2}{*}{ Progeny } & \multirow{2}{*}{$\begin{array}{l}1981\left(\sigma_{P}\right) \\
\mathrm{GH}\end{array}$} & \multicolumn{2}{|c|}{$1982\left(\sigma_{P}\right)$} & \multicolumn{2}{|c|}{$1983\left(\sigma_{G}\right)$} & \multicolumn{2}{|c|}{$1983\left(\sigma_{P}\right)$} \\
\hline & & BB & MURR & $\mathrm{BB}$ & MURR & $\mathrm{BB}$ & MURR \\
\hline $\mathrm{C} 1$ & $33 \cdot 7$ & $3 \cdot 4$ & $7 \cdot 1$ & $11 \cdot 9$ & 8.9 & $20 \cdot 0$ & $6 \cdot 4$ \\
\hline $\mathrm{C} 2$ & $27 \cdot 4$ & $9 \cdot 3$ & $10 \cdot 9$ & 0.0 & 0.6 & $3 \cdot 4$ & $3 \cdot 1$ \\
\hline $\mathrm{C} 3$ & $17 \cdot 6$ & 0.7 & $8 \cdot 2$ & 0.0 & $0 \cdot 0$ & 0.8 & 1.6 \\
\hline $\mathrm{C} 4$ & $25 \cdot 1$ & $5 \cdot 4$ & $7 \cdot 8$ & 0.7 & $0 \cdot 1$ & $5 \cdot 2$ & $2 \cdot 2$ \\
\hline $\mathrm{C} 5$ & $1 \cdot 5$ & 0.4 & $1 \cdot 5$ & 0.3 & 0.0 & $5 \cdot 0$ & $1 \cdot 2$ \\
\hline C6 & $19 \cdot 2$ & $7 \cdot 2$ & $11 \cdot 3$ & $3 \cdot 5$ & $2 \cdot 7$ & $13 \cdot 3$ & $7 \cdot 8$ \\
\hline C7 & $28 \cdot 1$ & $20 \cdot 3$ & 28.9 & $7 \cdot 1$ & 8.9 & $18 \cdot 1$ & $5 \cdot 8$ \\
\hline $\mathrm{C} 8$ & $11 \cdot 7$ & $2 \cdot 1$ & $0 \cdot 1$ & $0 \cdot 0$ & 0.0 & 1.4 & 0.1 \\
\hline
\end{tabular}

b. Observed

\begin{tabular}{|c|c|c|c|c|c|c|c|}
\hline \multirow[b]{2}{*}{ Progeny } & \multirow{2}{*}{$\begin{array}{l}1981 \\
\mathrm{GH}\end{array}$} & \multicolumn{2}{|c|}{$1982^{\prime}$} & \multicolumn{2}{|c|}{$1983^{\prime \prime}$} & \multicolumn{2}{|c|}{$1984^{\prime \prime \prime}$} \\
\hline & & BB & MURR & $\mathrm{BB}$ & MURR & BB & MURR \\
\hline $\mathrm{C} 1$ & $21 \cdot 7$ & $4 \cdot 6$ & $6 \cdot 1$ & $15 \cdot 7$ & $5 \cdot 7$ & $32 \cdot 0$ & $24 \cdot 0$ \\
\hline $\mathrm{C} 2$ & $17 \cdot 0$ & $8 \cdot 6$ & $6 \cdot 1$ & $2 \cdot 9$ & $1 \cdot 4$ & $16 \cdot 0$ & $8 \cdot 0$ \\
\hline C3 & $12 \cdot 7$ & $2 \cdot 0$ & $5 \cdot 4$ & 0.0 & $1 \cdot 4$ & $4 \cdot 0$ & 0.0 \\
\hline $\mathrm{C} 4$ & $13 \cdot 7$ & $3 \cdot 7$ & $5 \cdot 2$ & 5.7 & $4 \cdot 3$ & $12 \cdot 0$ & $4 \cdot 0$ \\
\hline $\mathrm{C} 5$ & $3 \cdot 8$ & $1 \cdot 2$ & $1 \cdot 2$ & $4 \cdot 3$ & $1 \cdot 4$ & $12 \cdot 0$ & 20.0 \\
\hline C6 & $13 \cdot 1$ & $5 \cdot 3$ & $9 \cdot 1$ & $5 \cdot 7$ & $8 \cdot 6$ & $24 \cdot 0$ & $20 \cdot 0$ \\
\hline $\mathrm{C} 7$ & $21 \cdot 4$ & $14 \cdot 6$ & $22 \cdot 2$ & $17 \cdot 1$ & $5 \cdot 7$ & $20 \cdot 0$ & $28 \cdot 0$ \\
\hline $\mathrm{C} 8$ & $8 \cdot 0$ & $2 \cdot 8$ & 0.0 & 2.9 & $1 \cdot 4$ & $4 \cdot 0$ & 0.0 \\
\hline
\end{tabular}

'= based on 200 clones; " = based on 70 clones; "' = based on 25 clones.

Table 4 Correlation coefficients between predicted and observed proportions of clones having an average score greater than (or equal to) 5.0. Predictions were based on the mean and $\sigma$ of the 70 clone samples

\begin{tabular}{|c|c|c|c|c|c|c|c|c|c|}
\hline \multirow{2}{*}{\multicolumn{2}{|c|}{$\begin{array}{l}\text { Predicted } \\
\text { from }\end{array}$}} & \multirow{3}{*}{$\begin{array}{l}1981 \\
\text { GH } \\
\mathbf{0 . 9 6}\end{array}$} & \multicolumn{2}{|c|}{1982} & \multicolumn{2}{|c|}{1983} & \multicolumn{2}{|c|}{1984} & \multirow[b]{2}{*}{ Mean } \\
\hline & & & BB & MURR & BB & MURR & BB & MURR & \\
\hline 1981 & $\mathrm{GH}$ & & 0.59 & 0.53 & 0.59 & 0.46 & 0.61 & 0.24 & 0.57 \\
\hline \multirow[t]{2}{*}{1982} & $\mathrm{BB}$ & $0 \cdot 70$ & 0.92 & 0.92 & 0.62 & 0.48 & $0 \cdot 37$ & 0.53 & 0.65 \\
\hline & MURR & $0 \cdot 30$ & 0.69 & 0.79 & 0.50 & 0.29 & $0 \cdot 32$ & 0.71 & 0.51 \\
\hline \multirow[t]{4}{*}{1983} & $\mathrm{BB}^{\prime \prime}$ & 0.73 & 0.40 & 0.49 & 0.91 & 0.63 & 0.85 & 0.74 & 0.68 \\
\hline & MURR" & 0.79 & 0.64 & $0 \cdot 71$ & 0.96 & 0.61 & 0.78 & 0.79 & 0.75 \\
\hline & BB & 0.70 & 0.55 & 0.66 & 0.93 & 0.80 & 0.90 & 0.88 & 0.77 \\
\hline & MURR & 0.68 & 0.52 & 0.63 & 0.66 & 0.91 & 0.89 & 0.74 & 0.72 \\
\hline
\end{tabular}

" predictions based on $\sigma_{G}$ while all others are based on $\sigma_{P}$.

The figures in bold type are those where observed and predicted are not independent as at least some of the data are in common. The figures in italics are correlations where the predictions were made in a later generation than the observed and so in practical terms are not useful but are included for completeness. Correlation coefficients of 0.66 or greater are significant at the 5 per cent level.

grounds, give more accurate predictions, the phenotypic variance gave a similar set of predictions. This raises the question of how great a contribution the variance makes to prediction at the target level set here. The relative contribution of mean and $\sigma$ to the prediction was investigated by regression of the predicted values (a) onto the mean and (b) the multiple regression onto the mean and $\sigma$. From these two regressions the coefficient of determination $\left(R^{2}\right)$ were calculated as the percentage of the regression item to the total sum of squares in the regression analysis. The differences between the two $R^{2}$ 's are given in table 5 , not only for a target value of 5 , but also for targets of 3,4 and 6. The differences increased, in general, as the target value rose. A target value 
Table 5 The average difference between the coefficients of determination $\left(R^{2}\right)$ obtained by the linear regression of the prediction, based only on the progeny means, onto the observed and the prediction based on the mean plus $\sigma_{P}$ onto the observed, for target values $(T)$ of $3,4,5$ and 6

\begin{tabular}{lllllr}
\hline Environment & $T>3$ & $T>4$ & $T>5$ & $T>6$ \\
\hline 1981 & GH & 0.8 & $1 \cdot 2$ & $4 \cdot 2$ & $6 \cdot 9$ \\
1982 & BB & 0.6 & $0 \cdot 1$ & $2 \cdot 8$ & $9 \cdot 2$ \\
& MURR & 1.9 & $5 \cdot 8$ & $0 \cdot 4$ & $12 \cdot 4$ \\
1983 & BB & $1 \cdot 3$ & $3 \cdot 8$ & $9 \cdot 4$ & $12 \cdot 1$ \\
& MURR & $0 \cdot 1$ & $1 \cdot 0$ & $7 \cdot 3$ & $17 \cdot 4$ \\
\hline
\end{tabular}

of 3 showed differences in $R^{2}$ ranging only from $0 \cdot 1$ to 1.9 while with a target value of 6 the differences ranged from 6.9 to $17 \cdot 4$. Thus it would seem, not surprisingly, that the variance becomes more important as the target value rises. Higher target values were not considered since only an extremely small proportion of clones were observed to exceed this target and the commercial cultivars grown suggested that such values were inappropriate.

The means of the 70 clones were therefore taken as the prediction of a cross's worth and correlated with the observed numbers greater than (or equal to) 5 (as was done for the mean plus $\sigma$ ), the coefficients of which are presented in table 6(i). As might be expected from the above findings, the agreement between the predicted and observed was not materially different when only the mean was used compared with when the mean and $\sigma$ was used. A further method of prediction is available. As was suggested by Powell, Caligari, McNicol and Jinks (1985) the actual number of lines falling into the required phenotypic category (in this case a score of greater or equal to 5) can be used as a predictor. The correlation coefficients, for predictions based on sample numbers with those observed, are given in table 6(ii). No values are given for predicted and observed at the same site in 1983 , since these data were by definition identical. Using this method it can be seen that again there was reasonably good agreement between predicted and observed numbers even over sites and years. The overall mean correlation for all these three prediction methods were $0.668,0.688$ and 0.628 for using the mean plus $\sigma$, the mean alone and the number observed in a sample, respectively. These three were obviously similar in magnitude to each other.

Although the correlation between the predicted and observed numbers as discussed above, is of interest to plant breeders, in most circumstances breeders are more concerned with ranking the crosses in terms of their ability to provide clones that are above the target value set. The rank

Table 6 Correlation coefficients for the relationship between predicted and observed numbers of lines scoring greater than (or equal to) $5 \cdot 0$

(i) Predictions based on the mean of the 70 clones.

\begin{tabular}{|c|c|c|c|c|c|c|c|c|c|}
\hline & & \multirow{2}{*}{$\begin{array}{l}1981 \\
\text { GH }\end{array}$} & \multicolumn{2}{|c|}{1982} & \multicolumn{2}{|c|}{1983} & \multicolumn{2}{|c|}{1984} & \multirow[b]{2}{*}{ Mean } \\
\hline & & & BB & MURR & BB & MURR & BB & MURR & \\
\hline 1981 & $\mathrm{GH}$ & 0.94 & 0.59 & 0.57 & 0.65 & 0.49 & 0.61 & 0.29 & 0.59 \\
\hline \multirow[t]{2}{*}{1982} & BB & 0.78 & $0 \cdot 86$ & 0.89 & 0.77 & 0.75 & 0.72 & 0.70 & 0.78 \\
\hline & MURR & 0.67 & 0.57 & 0.77 & 0.57 & 0.56 & 0.56 & 0.59 & 0.61 \\
\hline \multirow[t]{2}{*}{1983} & B B & 0.69 & 0.58 & 0.71 & $0 \cdot 80$ & 0.76 & 0.90 & 0.90 & 0.76 \\
\hline & MURR & 0.75 & 0.47 & 0.69 & $0 \cdot 70$ & 0.81 & 0.81 & $0 \cdot 70$ & $0 \cdot 70$ \\
\hline
\end{tabular}

(ii) Predictions based on the number of lines observed in a sample.

\begin{tabular}{llllllllll}
\hline & \multirow{2}{*}{1981} & \multicolumn{2}{c}{1982} & \multicolumn{2}{c}{1983} & \multicolumn{2}{c}{1984} \\
& & GH & BB & MURR & BB & MURR & BB & MURR & Mean \\
\hline 1981 & GH & $\mathbf{0 . 9 3}$ & 0.53 & 0.51 & 0.56 & 0.55 & 0.61 & 0.20 & 0.56 \\
1982 & BB & 0.64 & $\mathbf{0 . 9 9}$ & 0.92 & 0.63 & 0.39 & 0.36 & 0.54 & 0.64 \\
& MURR & 0.74 & 0.96 & $\mathbf{0 . 9 8}$ & 0.64 & 0.48 & 0.42 & 0.54 & 0.68 \\
1983 & BB & 0.72 & 0.63 & 0.69 & - & 0.60 & 0.75 & 0.81 & 0.70 \\
& MURR & 0.49 & 0.37 & 0.55 & 0.60 & - & 0.76 & 0.62 & 0.56 \\
\hline
\end{tabular}

The figures in bold type are those where observed and predicted are not independent as at least some of the data are in common. The figures in italics are correlations where the predictions were made in a later generation than the observed and so in practical terms are not useful but are included for completeness. Correlation coefficients of 0.66 or greater are significant at the 5 per cent level. 
correlations were estimated for all three different prediction systems for the target values of $3,4,5$ and 6 . The picture they gave was very similar to that already found for numbers. Again some of the correlation coefficients failed to reach formal significance due to the low numbers of degrees of freedom $(7 \mathrm{df})$ but their averages again left little doubt of their validity. Averaged over years and sites the rank correlations were all reasonably high but the highest target value (i.e., $>6$ ) gave the lowest coefficients.

It was noted in Material and Methods that the two sites were subject to somewhat different agronomic conditions, mainly in terms of BB having a shorter growing season. The question arises as to whether cross prediction using results of one site gives, on average, a better prediction for that site as opposed to the other one. In table 7 the rank correlation coefficients, averaged over years, are given for $\mathrm{BB}$ and MURR. The correlation coefficients did not differ greatly but of the 24 cases given, 18 had a higher coefficient with the same site. Of the remaining 6 cases, one showed the average correlation coefficient to be equal while 5 were the opposite way round. This suggests a tendency for the prediction to favour the site at which they were made but not to do so greatly. A further point of note is that of the 5 cases the other way round, 4 were associated with the two higher target values.

\section{CONCLUSIONS}

For the character visual appraisal, the mean and $\sigma$ provide a good prediction of the number of clones that will exceed (or equal) a given target value. These predictions hold good over a number of years at two contrasting locations. Further, it was clear that $\sigma$ added increasingly to the accuracy as the target value increased but was not a major component in the prediction. It was therefore not surprising that using the mean alone gave acceptable predictions. Another method of prediction which utilised the observed number of clones in a sample to predict the number that would be obtained in larger samples and in different environments was also satisfactory.

Plant breeders are generally more concerned with the ranking of the crosses, in terms of their ability to produce commercial cultivars, than the predicted numbers per se. When the predictions were carried out on this basis the rank correlations showed good agreement between observed and expected. There appeared to be a slight tendency for the predictions to agree more closely with observations at the same site than at the other site, when averaged over years. This tendency was not great but might need to be taken into account in a breeding programme where large numbers of progenies are being handled and hence even small differences could produce significant effects.

Table 7 Rank correlation coefficients averaged over all years for the four target values $(T=3,4,5$ and 6$)$ and for the three prediction methods

(i) Predictions based on the mean and $\sigma$.

\begin{tabular}{|c|c|c|c|c|c|c|c|c|}
\hline & \multicolumn{2}{|c|}{$T>3$} & \multicolumn{2}{|c|}{$T>4$} & \multicolumn{2}{|c|}{$T>5$} & \multicolumn{2}{|c|}{$T>6$} \\
\hline & $\mathrm{BB}$ & MURR & BB & MURR & BB & MURR & $\mathrm{BB}$ & MURR \\
\hline BB & $0 \cdot 89$ & 0.73 & $0 \cdot 72$ & 0.66 & 0.76 & 0.72 & $0 \cdot 40$ & 0.55 \\
\hline MURR & 0.79 & 0.87 & $0 \cdot 72$ & 0.73 & $0 \cdot 70$ & $0 \cdot 76$ & $0 \cdot 38$ & 0.66 \\
\hline
\end{tabular}

(ii) Predictions based on the mean.

\begin{tabular}{|c|c|c|c|c|c|c|c|c|}
\hline & \multicolumn{2}{|c|}{$T>3$} & \multicolumn{2}{|c|}{$T>4$} & \multicolumn{2}{|c|}{$T>5$} & \multicolumn{2}{|c|}{$T>6$} \\
\hline & $\mathrm{BB}$ & MURR & BB & MURR & BB & MURR & $\mathrm{BB}$ & MURR \\
\hline BB & 0.90 & 0.79 & 0.81 & 0.77 & 0.83 & 0.86 & 0.57 & 0.78 \\
\hline MURR & 0.76 & 0.86 & 0.61 & 0.66 & 0.66 & 0.73 & 0.38 & 0.65 \\
\hline
\end{tabular}

(iii) Predictions based on sample numbers.

\begin{tabular}{|c|c|c|c|c|c|c|c|c|}
\hline & \multicolumn{2}{|c|}{$T>3$} & \multicolumn{2}{|c|}{$T>4$} & \multicolumn{2}{|c|}{$T \gg 5$} & \multicolumn{2}{|c|}{$T \gg 6$} \\
\hline & $\mathrm{BB}$ & MURR & $\mathrm{BB}$ & MURR & $\mathrm{BB}$ & MURR & $\mathrm{BB}$ & MURR \\
\hline BB & 0.84 & 0.82 & 0.79 & 0.65 & 0.71 & 0.69 & 0.19 & 0.40 \\
\hline MURR & 0.75 & 0.86 & 0.65 & 0.65 & 0.72 & 0.68 & 0.37 & 0.73 \\
\hline
\end{tabular}


It would clearly be of interest to examine such predictions over other characters or combinations of characters and to investigate them in the practical context of a potato breeding programme.

\section{REFERENCES}

BROWN, J., CALIGARI, P. D. S., MACKAY, G. R. AND SWAN, G. E. L. 1984. The efficiency of seedling selection by visual preference in a potato breeding programme. I. Agric. Sci., 103, 339-346.

BROWN, J., AND CALIGARI, P. D. S. 1986. The efficiency of seedling selection for yield and yield components in a potato breeding programme $Z$. Pflanzenzucht., 96, 53-62.

BROWN, J., CALIGARI, P. D. S., MACKAY, G. R. AND SWAN, G. E. L. 1986. The efficiency of visual selection in early generations of a potato breeding programme. (submitted).

EROWN, J., CALIGARI, P. D. S. AND MACKAY, G. R. 1986. The repeatability of progeny means in the early generations of a potato breeding programme. (submitted).

CALIGARI, P. D. S., POWELL, W. AND JINKS, J. L. 1985. The use of doubled haploids in barley breeding 2. An assessment of univariate cross prediction methods. Heredity, 53, 353358.

CALIGARI, P. D. S. AND POWELL, W. 1986. The effects of competitive interactions on variances and on seed germination in spring barley (Hordeum vulgare). Heredity, 57, 331-334.

HOLdEN, J. H. W. 1977. Potato breeding at Pentlandfield. In Scottish Plant Breeding Station Ann. Rep., pp. 66-97.

JINKS, J. L. AND POONI, H. S. 1976. Predicting the properties of recombinant lines derived by single seed decent. Heredity, 45, 305-312.

MACKAY, G. R. 1982. Breeding for resistance to pests and diseases. In Proceeding Quality Seed Potato in Scotland, Proc. Scottish Soc. for Crop Res. Bull., 1 pp. 27-36.
POONI, H. S. AND JINKS, J. L. 1978. Predicting the properties of recombinant inbred lines derived by single seed decent for two or more characters simultaneously. Heredity, 40, 349-361.

POONI, H. S. AND JINKS, J. L. 1985. Predicting the properties of first cycle inbreds and second cycle hybrids extracted from two, three and four parent crosses. Heredity, 54, $397-411$.

POONI, H. S., JINKS, J. L. AND YOHANNES, D. 1985. Predicting the properties of random inbreds and second cycle hybrids using progeny families and hierarchical selfs of a four parent cross. Heredity, 55, 111-119.

POWELL, W., CALIGARI, P. D. S., MCNICOL, J. W. AND JINKS, J. L. 1985. The use of doubled haploids in barley breeding. 3 . An assessment of multivariate cross prediction methods. Heredity, 55, 249-254.

POWELl, W., CAligari, P. D. S., GOUDAPPEL, P. H. AND THOMAS, W. T. B. 1985. Competitive effects in monocultures and mixtures of spring barley (Hordeum vulgare). Theor. Appl. Genet., 71, 443-450.

POWELl, W., CALIGARI, P. D. S., PHILliPS, M. S. AND JINKS, J. L. 1986. The measurement and interpretation of genotype by environment interactions in spring barley (Hordeum vulgare). Heredity, 56, 255-262.

REINBERGS, E., PARK, S. J. AND SONG, L. S. P. 1976. Early identification of superior barley crosses by the double haploid technique. Z. Pflanzenzucht., 76, 215-224.

SIMPSON, E. AND SNAPE, J. W. 1979. Cross prediction for yield using doubled haploid lines. Barley Genet. News., 9, 95-97.

SNAPE, J. W. 1982. Predicting the frequencies of transgressive segregants for yield and yield components in wheat. Theor. Appl. Genet., 62, 127-134.

TAPSELL, C. R. AND THOMAS, W. T. B. 1983. Cross prediction studies on spring barley. 2. Estimation of genetical and environmental control of yield and its component characters. Theor. Appl. Genet., 64, 353-358.

THOMAS, W. T. B. AND TAPSELL, C. R. 1983. Cross prediction studies on spring barley 1. Estimation of genetical and environmental control of morphological and maturity characters. Theor. Appl. Genet., 64, 345-352. 